\title{
Nasal Substitution in Sarawak Malay Dialect
}

\author{
Sharifah Raihan Syed Jaafar ${ }^{1}$ \\ ${ }^{1}$ School of Language Studies and Linguistics, Faculty of Social Sciences and Humanities, University \\ Kebangsaan Malaysia, Malaysia \\ Correspondence: Sharifah Raihan Syed Jaafar, School of Language Studies and Linguistics, Faculty of Social \\ Sciences and Humanities, University Kebangsaan Malaysia, Malaysia. E-mail: s_raihan@ukm.my
}

\author{
Received: November 30, 2012 Accepted: February 8, 2013 Online Published: March 28, 2013 \\ doi:10.5539/ass.v9n4p92 \\ URL: http://dx.doi.org/10.5539/ass.v9n4p92
}

\begin{abstract}
This study discusses a phonological strategy, i.e. nasal substitution, which is regularly applied to eliminate nasal and voiceless obstruent clusters from emerging in the surface representation. As claimed in previous studies, the clusters are disallowed from emerging in the surface representation. Nasal substitution is therefore applied as a strategy to get rid of those clusters. In this paper, I will present how nasal substitution is applied in the Sarawak Malay dialect by focusing on two morphological environments in which the clusters emerge, i.e. within roots and at prefix junctures. The data obtained from interviews show that nasal and voiceless obstruent clusters are not completely disallowed in the dialect, as nasal substitution is only active at prefix junctures and not within roots. Furthermore, in this dialect, voiced obstruents also undergo nasal substitution. These phenomena are accounted for in this study by proposing CRISP-EDGE $[\sigma]$ and UNIFORMITY-ROOT in the grammar of the Sarawak dialect of Malay.
\end{abstract}

Keywords: nasal substitution, Sarawak dialect, Malay, optimality theory

\section{Introduction}

It has widely been claimed in the literature that nasal and voiceless obstruent clusters are not allowed to emerge in the surface representation. The occurrence of those clusters in the input representation has therefore always been resolved by applying phonological strategies, e.g. nasal substitution, nasal deletion, denasalisation, post-nasal voicing and vowel epenthesis (Pater, 2001). A language may apply one or more strategies to avoid clusters in the surface representation. For example, in the group of Malay native words, nasal substitution is applied when the input contains a nasal and voiceless obstruent to break up a cluster, whereby the voiceless obstruent is deleted and leaves its place of articulation to the preceding nasal. This strategy is however not applied to monosyllabic foreign words. Vowel epenthesis is applied instead (Syed Jaafar, 2010).

Why are voiceless obstruents following nasals disfavoured, while voiced obstruents are not? This is something that needs to be discussed by taking the phonetic aspect of voiceless and voiced obstruents into account. A nasal consonant is produced by lowering the velum in the mouth, allowing air to exit freely through the nose. The change from a nasal consonant to an obstruent causes the velum to be raised and this block the airflow from passing through the nose (Kager, 1999: 61). However, the process of raising the velum takes some time and is incomplete at the time when the obstruent begins. At this point, there is still a little air flowing out through the nose because the velum is not raised high enough. This is called 'nasal leak' (Kager, 1999). As the presence of a voiceless obstruent following a nasal segment causes difficulty to the system of human articulation, the clusters undergo some repair strategies. As we will see in this analysis, the clusters at prefix junctures also undergo a repair strategy, i.e. nasal substitution, e.g. $/ \mathrm{y}+\mathrm{kira} / \rightarrow$ [nira] and $/ \mathrm{y}+$ toleh $/ \rightarrow$ [noleh].

It should be mentioned that the reverse state occurs in the dialect if the obstruent is voiced. This raises the question of how this phonological process can be resolved in OT analysis. OT as a current theory in phonology has introduced different ways of analysing data, with no more rules or intermediate phonological representations applied, as in a rule-based approach. The innovation that OT offers compared to other alternative theories in phonology has therefore led this study to apply it to analyse the case of nasal substitution in the Sarawak Malay dialect (Note 1) (henceforth, SMD). To deal with the issue of nasal substitution in SD, it is necessary to posit a constraint that is able to rule out a nasal plus a voiced obstruent cluster, so that a candidate with nasal substitution can emerge as the optimal output. Therefore, I suggest that CRISP-EDGE [ $\sigma$ ] should be added to the 
constraint ranking of SMD.

\section{Methodology}

The research method that was used to conduct this study was interviews. A number of native speakers of the SMD were interviewed. In order to get the phonological patterns of the dialect, ten SMD speakers were interviewed. Data were collected in a city called Kuching, where the people speak the standard dialect of SMD.

The data from the interviews were transcribed and categorised into two groups according to the morphological environments in which the nasal and voiceless obstruent clusters occur, i.e. (1) within roots, and (2) at prefix junctures.

\section{Analysis}

In this section I discuss how nasal and voiceless obstruent clusters in two morphological environments, i.e. (1) root-internal, and (2) prefix junctures, behave. I begin the discussion of nasal and voiceless obstruent clusters within roots by first observing the data listed in the following table:

Table 1. Nasal and voiceless obstruent clusters within roots

\begin{tabular}{llll}
\hline & Input & SM & SD \\
\hline a. & /mampan/ & mampan & mampan \\
b. & $/$ mampu/ & mampu & mampu \\
c. & $/$ tempay/ & tempan & timpan \\
d. & $/$ sumpit/ & sumpet & umpit \\
e. & /montah/ & montah & manta \\
f. & /sampai/ & sampai & sampey \\
g. & /tampar/ & tampa & nampa \\
h. & /pantul/ & pantol & pantol \\
i. & $/$ lompat/ & lompat & lompat \\
j. & tempay/ & tempan & timpay \\
k. & $/$ lantai/ & lantai & lante \\
l. & /kampoy/ & kampon & kampon \\
\hline
\end{tabular}

As presented in the data above, we see that nasal and voiceless obstruent clusters are treated differently in the dialect. The clusters are not entirely prohibited from emerging in the surface as they do not undergo nasal substitution or other repair strategies to eliminate the clusters within a root. In this morphological environment, the voiceless obstruent following a nasal segment would normally be retained. As illustrated in the above examples, nasal and voiceless obstruent clusters within the roots appear in the surface representation in the SMD. Observe that the clusters appear in words such as [mampan], [timpan] and [nampar].

A question that can be posed here is: Why do nasal and voiceless obstruent clusters emerge in the surface representation in the dialect since Malay bans the clusters from occurring at surface level? Before I offer the OT account, it is worth knowing that such a situation that occurs in Sarawak also arises in other languages. One of those is Indonesian. In this language, the nasal substitution that is generally applied to eliminate nasal and voiceless obstruent sequences at prefix-root junctures is blocked at root-internal level as well. The consequence of blocking nasal substitution in Indonesian is a sequence of homorganic nasal and voiceless obstruents in the surface representation, as exemplified below:

Root-internal occurrences of NC in Indonesian (from Pater, 1999: 75; 2001)

$\begin{array}{lll}\text { /ompat/ } & \text { [ompat }] & \text { 'four' } \\ \text { /untuk/ } & \text { [untuk] } & \text { 'for' } \\ \text { /munkin/ } & \text { [munkin] } & \text { 'maybe' }\end{array}$

It is clear from the above examples that nasal and voiceless obstruent clusters occur in root-internal positions in Indonesian as well. Such a problem occurring in Indonesian has received much attention from theoretical 
linguists, particularly within OT (e.g. Pater 1999, 2001), as to why nasal substitution is blocked within roots. This poses a challenge to the theory when explaining the blocking of nasal substitution at root-internal positions. In explaining the lack of nasal substitution at root-internal positions, McCarthy and Prince (1994b, cited in Pater, 1996) claim that 'a large number of disparate phonological phenomena for instance, reduplicative and otherwise, result in a stricter faithfulness requirement within the root than elsewhere in the word, that is the relative markedness of roots' (see also Urbanczyk, 1996). In OT, this situation is accounted for, as faithfulness requirements are more strictly applied within the root than in non-root morphemes, such as affixes (McCarthy and Prince, 1995, cited in Kager, 1999: 75). To capture this situation, McCarthy and Prince (1994a) proposed a general ranking schema whereby root-specific versions of faithfulness constraints are ranked higher than the general version of these constraints: Root-Faithfulness $>>$ Faithfulness.

Since nasal substitution is also blocked within roots in the SMD, a root-specific constraint, which bans root-internal nasal substitution, is needed for the analysis of SMD. The relevance constraint of faithfulness, that is able to capture the blocking of nasal substitution, is UNIFORMITY, as defined below:

UNIFORMITY ('No Coalescence') (McCarthy and Prince, 1999: 296)

No element of $S_{2}$ has multiple correspondents in $S_{1}$.

For $\mathrm{x}, \mathrm{y} \in \mathrm{S}_{1}$ and $\mathrm{z} \in \mathrm{S}_{2:}$ if $\mathrm{x} \mathrm{R} \mathrm{z}$ and $\mathrm{y} \mathrm{R} \mathrm{z}$, then $\mathrm{x}=\mathrm{y}$.

We will see then that UNIFORMITY, which is the general version of the faithfulness constraint, is ranked beneath the root-specific version of this constraint, i.e. UNIFORMITY-ROOT, in the constraint ranking of SMD. The root specific constraint, UNIFORMITY-ROOT, is defined below:

\section{UNIFORMITY-ROOT}

The output reflects the precedence structure of the input segments of the roots, and vice versa.

In the case where nasal substitution is blocked root-internally, UNIFORMITY-ROOT is ranked high to allow output containing a sequence of nasal and voiceless obstruents. There is a functional explanation for why nasal and voiceless obstruent sequences are allowed to be present root-internally. As asserted in Pater (1999), root-internal segments are more resistant to phonological processes than segments in other positions (cited in Kager, 1999: 75). In some of the morphological literature (e.g. Mascaro, 1976; Kiparsky, 1982, 1993b; cf. Kager, 1999) it is said that 'there is a well-known class of processes that apply only across morphemes but fail to apply within the roots' (cf. Kager, 1999: 75). That is the reason why sequences of nasal and voiceless obstruents function root-internally in Sarawak and thus do not undergo the regular process, i.e. nasal substitution.

Since root-internal nasal and voiceless obstruent clusters in SMD are not resolved by nasal substitution, we need a root-specific faithfulness constraint, as discussed above, i.e. UNIFORMITY-ROOT, which is able to block clusters from undergoing nasal substitution. By considering UNIFORMITY-ROOT in the ranking, a candidate without nasal substitution is preferred, i.e. [mampan] is preferred over *[mapan], and thus emerges as the optimal output.

This solution of epenthesizing schwa can also be applied to eliminate a sequence of nasal and voiceless obstruents within a root. Thus, the potential candidate if schwa epenthesis were to apply is *[kaməpon]. This candidate involves an additional correspondent in the output. Under Correspondence Theory (see below) the constraint that this candidate violates is DEP-IO.

CORRESPONDENCE THEORY (McCarthy and Prince, 1995: 262)

Given two strings $S_{1}$ and $S_{2}$, correspondence is the relation $\Re$ between the elements of $S_{1}$ and those of $S_{2}$. Elements (Note 2) $\alpha \quad S_{1}$ and $\beta \quad S_{2}$, are referred to as correspondents of each other when $\alpha \mathfrak{R} \beta$.

The constraint DEP-IO is violated by the candidate *[kaməpon], because the schwa segment in the output does not have a correspondent in the input, as required by the constraint:

\section{DEP-IO}

Every segment in the input must have a correspondent in the output.

I present the following correspondence diagram for DEP-IO violation to show how the candidate *[kaməpon] violates this faithfulness constraint:

Correspondence diagram for DEP-IO violation 


$\begin{array}{llll}\text { Input: } & \left.\right|_{\text {Output: }} ^{y_{1}} & & \left.\right|_{\mathrm{y}_{1}} ^{\mathrm{p}_{2}} \\ & \partial & \mathrm{p}_{2}\end{array}$

For this constraint, DEP-IO, and the other two faithfulness constraints discussed above, UNIFORMITY and UNIFORMITY-ROOT, I establish the following constraint ranking for SMD:

DEP-IO >> UNIFORMITY-ROOT >> UNIFORMITY

\begin{tabular}{|l||c|c|c|}
\hline$/ \mathrm{kam}_{1} \mathrm{p}_{2} \mathrm{oy} /$ & DEP-IO & UNIFORMITY-ROOT & UNIFORMITY \\
\hline \hline a. ${ }^{\circ a m_{1}} \mathrm{p}_{2} \mathrm{oy}$ & & & \\
\hline b. $\mathrm{kam}_{12} \mathrm{o \eta}$ & & $* !$ & \\
\hline c. $\mathrm{kam}_{1} ə \mathrm{p}_{2} \mathrm{o \eta}$ & $* !$ & & \\
\hline
\end{tabular}

Here we see that epenthesis is not a better way to break up clusters as DEP-IO is highly ranked, as in candidate (c). The root-specific constraint, UNIFORM-ROOT, blocks candidate (a) from undergoing nasal substitution. Therefore, it is chosen as the winner. However, candidate (b), with nasal substitution, violates UNIFORMITY-ROOT. I illustrate below the difference between [ $\left.\mathrm{kam}_{1} \mathrm{p}_{2} \mathrm{o}\right]$ ] and [kam $\left.\mathrm{ka}_{12} \mathrm{o}\right]$, as candidates (a) and (b), respectively. Candidate (b) with nasal substitution violates the root-faithfulness constraint, UNIFORMITY-ROOT. The subscripted number is used to indicate the correspondence relationship.

Correspondence diagram for UNIFORMITY-ROOT violation

$$
\begin{aligned}
& \text { Candidate (a) } \\
& \mathrm{ka} \mathrm{m} \mathrm{p}_{1}
\end{aligned}
$$$$
\text { Candidate (b) }
$$

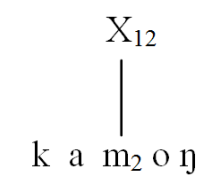

As well as the above candidates, we shall consider other potential candidates that might be generated. Another potential candidate that must be taken into consideration is *[kapon]. In *[kapon], the nasal segment is deleted and this results in one segment in the input having no correspondent in the output. The relation between input and output is called Faithfulness- $\mathrm{IO}$, where faithfulness to the input and output identity is a type of requirement in which a pair of representations must be identical, as stated in Correspondence Theory (McCarthy and Prince, 1995, cited in Kager, 1999: 24). In this case, the Faithfulness-IO constraint that is crucial to account for nasal deletion is MAX-IO:

MAX-IO (Kager, 1999: 24)

Every segment in the input must have a correspondent in the output.

The above constraint requires every element in the input to have a correspondent in the output. The violation of MAX-IO in the suboptimal candidate *[kapon] is illustrated in the correspondence diagram, below:

Correspondence diagram for nasal deletion: [kampon] $\rightarrow *$ [kapon].

$\begin{array}{ll}\text { Input } & \mathrm{m} \\ \text { Output } & \mathrm{p}\end{array}$

Considering the potential candidate *[kapon] in the tableau, I establish the following part of the constraint ranking: DEP-IO >> MAX-IO >> UNIFORM-ROOT >> UNIFORM. Now we have two relevant faithfulness constraints in the ranking, DEP-IO and MAX-IO, for further evaluation. 
DEP-IO $>>$ MAX-IO $>>$ UNIFORM-ROOT $>>$ UNIFORMITY

\begin{tabular}{|l||c|c|c|c|}
\hline$/ \mathrm{kam}_{1} \mathrm{p}_{2}$ on/ & DEP-IO & MAX-IO & UNIFORMITY-ROOT & UNIFORMITY \\
\hline \hline a. ${ }^{\circ} \mathrm{Kam}_{1} \mathrm{p}_{2}$ on & & & & \\
\hline b. $\quad \mathrm{kam}_{12}$ on & & & $* !$ & \\
\hline c. $\quad \mathrm{kam}_{1}$ əp $\mathrm{p}_{2}$ on & $* !$ & & & \\
\hline d. $\quad \mathrm{kap}_{2}$ on & & $* !$ & & \\
\hline
\end{tabular}

As can be seen, candidates (c) and (d), which undergo schwa epenthesis and nasal deletion respectively, to eliminate nasal and voiceless obstruent clusters, are ruled out because the candidates violate DEP-IO and MAX-IO, respectively. Candidate (b), which undergoes nasal substitution, violates UNIFORMITY-ROOT. Although nasal substitution is a process of merging two segments in the input into a single segment in the output, which results in one segment less in the output, it does not however violate the faithfulness constraint, MAX-IO, as with candidate (b). Indeed, MAX-IO requires every segment in the input to have a correspondent in the output; in nasal substitution, however, the two [mp] segments share a single output correspondent (Pater, 2001: 167). Therefore, candidate (a), with lack of nasal substitution, is chosen as the optimal output, as this candidate violates none of the constraints.

We now should move on to discuss nasal and voiceless obstruent clusters at prefix-root junctures in the SMD. In the above discussion, we noted that the clusters are preserved in the surface representation as the regular process, i.e. nasal substitution is not applied to break up clusters. A question that can be raised here is: Does the situation which occurs in root-internal positions also occur at prefix junctures in the dialect? Before we proceed to the analysis, let us first observe some relevant data:

Table 2. Nasal and voiceless obstruent clusters at prefix junctures

\begin{tabular}{|c|c|c|c|c|}
\hline & Input & SM & Input & SMD \\
\hline a. & /məy+ kalah/ & məyalah & $/ \mathrm{y}+$ kalah/ & yãlah \\
\hline b. & /mən+ pantul/ & məmantol & $/ \mathrm{y}+$ pantul $/$ & mãntol \\
\hline c. & /mən+ padah/ & məmadah & $/ \mathrm{y}+$ padah $/$ & mãdah \\
\hline d. & /məy+ sumpit/ & mə umpet & $/ \mathrm{y}+$ sumpit/ & ũmpyt \\
\hline e. & /məy+ toleh/ & mənoleh & $/ \mathrm{y}+$ toleh $/$ & nõleh \\
\hline f. & /məy+ sunat/ & mə unat & $/ \mathrm{y}+$ sunat $/$ & ũnãt \\
\hline g. & /məy+ kuray/ & məyuran & $/ \mathrm{y}+$ kuray/ & yũra \\
\hline h. & /məy+ kira/ & mənira & $/ \mathrm{y}+$ kira/ & yĩra \\
\hline i. & /məy+ sumbat/ & mə umbat & $/ \mathrm{n}+$ sumbat$/$ & ũmbat \\
\hline j. & /məy+ kumpul/ & məyumpol & /y+ kumpul/ & yũmpul \\
\hline
\end{tabular}

The phonology of the Sarawak dialect presented above can be summarized as follows: i) a nasal segment assimilates to the place of articulation of a following voiceless obstruent; (ii) a voiceless obstruent that follows a nasal segment is deleted; and (iii) the first vowel following a nasal segment is nasalised.

Observe that the prefix /mən+/ which is regularly used in SM appears as it is in the surface representation, e.g. $/ \mathrm{m} ə \mathrm{y}+\mathrm{kalah} / \rightarrow$ [məyalah] and $/ \mathrm{məy}+$ toleh/ $\rightarrow$ [mənoleh]. In SMD, however, the prefix emerges without the first two segments, i.e. nasal segment $/ \mathrm{m} /$ and schwa $/ \mathrm{\partial} /$. Only the final nasal in the prefix appears in the surface representation. The words $/ \mathfrak{y}+\mathrm{kalah} /$ and $/ \mathrm{y}+$ toleh/ are realised as [yãlah] and [nõleh], respectively. The losing of the first two segments of the prefix, as occurred in SD, can be explained as the prefix undergoing syllable reduction. Syllable reduction has been claimed by previous scholars to be a common case in most Malay dialects, such as in Kedah (Collins, 1986: 10; Omar, 1986: 99), Kelantan (Che Kob, 1985: 270), Terengganu (Omar, 1985: 287), Pahang (Collins, 1983: 104) and Perak (Ahmad, 1991: 55). Thus, in this analysis of SD, I am assuming that the prefix also undergoes syllable reduction as only one segment, i.e. the final nasal of the prefix emerges in the output. Hence, I posit that $/ \mathrm{y}+/$ is the underlying form of prefix in the SMD, not $/ \mathrm{moy}^{+/}$as in SM. Thus $/ \mathrm{y}+/$ will be used in this analysis to represent the underlying form of SD. 
Now I begin the OT analysis to account for SD. The issue now at hand is the occurrence of nasal and voiceless obstruent clusters at prefix junctures in SMD. We see how the clusters are resolved in the dialect by discussing the relevant constraints that play a significant role in preventing clusters from occurring in the surface representation. An important constraint in this analysis is CRISP-EDGE, which bans any element linked to a prosodic word and may be linked to a prosodic category external to that prosodic word; this will be used instead of *NC to avoid nasal and voiceless obstruent clusters in the surface representation.

Why CRISP-EDGE is preferred over *NC ? CRISP-EDGE is crucial to rule out nasal and voiced obstruent clusters as well as nasal and voiceless obstruent clusters in the surface representation. In order to account for voiced obstruent nasal substitution in the SMD, which allows voiced obstruents to undergo nasal substitution, I will make use of the constraint CRISP-EDGE $[\sigma]$. As we shall see later in this analysis, CRISP-EDGE $[\sigma]$ becomes crucial in accounting for nasal and voiced obstruent clusters at prefix-root junctures in SD. Below is how CRISP-EDGE $[\sigma]$ is defined:

\section{CRISP-EDGE $[\sigma]$}

No element belonging to a syllable may be linked to an adjacent syllable.

As mentioned above, CRISP-EDGE $[\sigma]$ excludes candidates with both nasal and voiceless/voiced obstruent clusters from the surface representation. This means that this constraint will prevent $*\left[\mathrm{n}_{1} \mathrm{t}_{2} \mathrm{oleh}\right]$ and $*[\mathrm{mb}$ ros $]$ from emerging as winners. The only candidate that this constraint prefers is a candidate with nasal substitution, i.e. a candidate without a nasal and voiceless/voiced obstruent cluster. The potential candidates are $\left[\mathrm{n}_{12} \mathrm{oleh}\right]$ and [moros]. Although these candidates obey CRISP-EDGE [ $\boldsymbol{\sigma}]$, they do not violate another constraint which requires edge segments in the input to preserve their segments at the edge of the corresponding prosodic structure, as stated in a constraint named EDGE-INTEGRITY, which is defined below:

EDGE INTEGRITY (McCarthy and Prince, 1995)

Edge segments in the input preserve their segments at the edge of the corresponding prosodic structure.

Bringing together all the constraints we have discussed so far, I establish the following part of the constraint hierarchy for SD: DEP-IO $>>$ MAX-IO $>$ UNIFORM-ROOT $>$ CRISP-EDGE $[\sigma]>$ EDGE-INTEG $>>$ UNIFORM.

Nasal and voiceless obstruent sequences at prefix-root junctures in Sarawak

\begin{tabular}{|l|c|c|c|c|c|c|}
\hline$/ \mathrm{n}_{1}+\mathrm{t}_{2} \mathrm{oleh} /$ & DEP-IO & MAX-IO & UNI-ROOT & CRISP-EDGE[ $\sigma]$ & EDGE-INTEG & UNI \\
\hline a. ${ }^{\varpi} \mathrm{n}_{12}$ oleh & & & & & $*$ & $*$ \\
\hline b. $\quad \mathrm{n}_{1} \mathrm{t}_{2}$ oleh & & & & $* !$ & & \\
\hline c. $\quad \mathrm{n}_{1}$ ət $\mathrm{t}_{2}$ oleh & $* !$ & & & & & \\
\hline d. $\quad \mathrm{t}_{2}$ oleh & & $* !$ & & & & \\
\hline
\end{tabular}

The above tableau shows that a sequence of nasal and voiceless obstruents is disfavoured in SMD. Therefore, candidate (b) is ruled out as it violates CRISP-EDGE. As we can see, schwa is epenthesized between the nasal segment and the initial voiceless obstruent of the base in candidate (c) to prevent clusters from emerging in the surface representation. This solution is, however, not a better way to avoid clusters as DEP-IO is highly ranked in the constraint ranking. As mentioned earlier, nasal deletion is another way to eliminate a sequence of nasal and voiceless obstruents in the surface representation. By applying nasal deletion, candidate (d) contains no nasal and voiceless obstruent clusters. This candidate therefore obeys CRISP-EDGE, as there is no element linked to a prosodic word which is linked to a prosodic category external to that prosodic word. However, this obedience to CRISP-EDGE results in the candidate violating a higher constraint in the ranking, i.e. MAX-IO, as a nasal segment in the prefix is deleted. As all the candidates have already been ruled out of the evaluation, candidate (a) emerges as the optimal output, as it only violates EDGE INTEGRITY and UNIFORMITY, which are lower constraints in the ranking.

We have just discussed how nasal and voiceless obstruent clusters are treated in the dialect. Now, I discuss nasal and voiced obstruent clusters. As mentioned earlier, voiced obstruents in this dialect also undergo nasal substitution, like voiceless obstruents do. It is worth mentioning that, from the interview data, voiced obstruents after nasal segments do not consistently undergo nasal substitution. In the following examples, I lay out the data showing voiced obstruents undergoing nasal substitution: 
Table 3. Nasal and voiced obstruent clusters at prefix junctures

\begin{tabular}{|c|c|c|c|c|}
\hline & Input & $\mathrm{SM}$ & Input & SMD \\
\hline a. & $/ \mathrm{məy}+\mathrm{ba}$ a/ & {$\left[\begin{array}{ll}\text { məmba } & a\end{array}\right]$} & $/ y+b a \quad a /$ & $\mathrm{ma} \quad \mathrm{a}$ \\
\hline b. & /məy + bərus/ & [məmberus] & $/ \mathrm{y}+$ bərus/ & mərus \\
\hline c. & /məy + gorey/ & [məygoren] & $/ \mathrm{y}+$ goren/ & yorey \\
\hline d. & /məy + guntin/ & [məygunteng] & $/ \mathrm{y}+$ guntiy/ & yuntin \\
\hline e. & /məy + gariy/ & [məygaren] & $/ \mathrm{y}+$ gariy $/$ & yarin \\
\hline
\end{tabular}

As we see in the above data, a voiced obstruent following a nasal segment also undergoes nasal substitution. For example, words like $/ \mathfrak{y}+$ ba a/ and $/ \mathfrak{y}+$ bərus/ are realized as [ma a] and [məros] and not as *[mba a] and *[mbəros], respectively. I now establish a new tableau, with the same constraint ranking as nasal and voiceless obstruent clusters, to account for sequences of nasals and voiced obstruents in the SMD.

\begin{tabular}{|c|c|c|c|c|c|c|}
\hline$/ \mathrm{y}_{1}+\mathrm{b}_{2}$ ərus/ & DEP-IO & MAX-IO & UNI-ROOT & CRISP-EDGE $[\sigma]$ & EDGE-INTEG & UNI \\
\hline a. $\mathrm{m}_{12}$ əros & & & & & $*$ & $*$ \\
\hline b. $\mathrm{m}_{1} \mathrm{~b}_{2} \partial \operatorname{ros}$ & & & & $* !$ & & \\
\hline c. $\mathrm{m}_{1} \partial \mathrm{b}_{2} \partial \mathrm{ros}$ & $* !$ & & & & & \\
\hline d. b $_{2}$ əros & & $* !$ & & & & \\
\hline
\end{tabular}

\section{Conclusion}

Analysis of the SMD shows that the dialect disfavours nasal and voiceless obstruent clusters only at prefix junctures. As we have seen in the analysis, the occurrence of clusters within roots is not resolved by nasal substitution, nor by any other phonological strategies. The clusters remain in this morphological environment. As discussed, a root-specific faithfulness constraint plays a significant role in the analysis. To ensure that sequences of nasal and voiceless obstruents do not undergo nasal substitution, a root-specific faithfulness constraint must be ranked higher than the general faithfulness constraint, and the relevant constraints for this are: UNIFORMITY ROOT $\gg$ UNIFORMITY. Therefore, we see such words as [kampon], [lompat], [pantol] and [əmpat] in the dialect.

In contrast, the occurrence of nasal and voiceless obstruent clusters at prefix junctures in the dialect is resolved by nasal substitution. We note from the above discussion that nasal substitution is not only applied to a voiceless obstruent following a nasal segment. Interestingly, this phonological strategy is also applied to voiced obstruents. Therefore, as we have seen, nasal and voiced obstruent clusters also undergo nasal substitution in the dialect. Both cases, voiced and voiceless nasal substitution that occur in the dialect, can be adequately accounted for by employing constraint-based analysis.

\section{Acknowledgments}

This research on the Sarawak dialect of Malay was funded by the Centre for Research and Instrumentation (CRIM), University Kebangsaan, Malaysia. The funding came from a Young Research Encouragement Grant (GGPM-2011-049).

\section{References}

Ahmad, Z. (1991). The phonology and morphology of the Perak dialect. Kuala Lumpur: Institute of Language and Literature.

Che Kob, A. (1985). Dialek geografi Pasir Mas. Publisher of the National University of Malaysia.

Collins, J. T. (1983). Dialek Pahang: rangka pengenalan (bahagian pertama). Kuala Lumpur: Institute of Language and Literature.

Kager, R. (1999). Optimality theory. Cambridge: Cambridge University Press. http://dx.doi.org/10.1017/CBO9780511812408

Kiparsky, P. (1982). From cyclic phonology to lexical phonology. In H. van der Hulst, \& N. Smith (Eds.), The structure of phonological representatitons (Part 2, pp. 131-176). Dordrecht: Foris. 
Kiparsky, P. (1993). Blocking in non-derived environments. In S. Hargus, \& E. Kaisse (Eds.), Phonetics and phonology IV: studies in lexical phonology (pp. 277-313). San Diego: Academic Press.

Mascaro, J. (1976). Catalan phonology and the phonological cycle. PhD thesis. MIT Distributed by Indiana Linguistics Club.

McCarthy, J. J., \& Prince, A. S. (1976). Faithfulness and reduplicative identity. Retrieved from http://ruccs.rutgers.edu/roa.html

McCarthy, J. J., \& Prince, A. S. (1999). Faithfulness and Identity in Prosodic Morphology. In Kager, R., Hulst, H., \& Zonneveld, W. (Eds.), 218-384.

Omar, A. (1985). Susur galur bahasa Melayu. Kuala Lumpur: Institute of Language and Literature.

Pater, J. (1996). *NC. Proceedings of the North East Linguistics Society, 26, 227-239.

Pater, J. (1999). Austronesian nasal substitution and other NC effects. In R. Kager, H. Hulst, \& W. Zonneveld (Eds.), The prosody-morphology interface (pp. 310-343).

Pater, J. (2001). Austronesian nasal substitution revisited. In L. Lombardi (Ed.), Segmental phonology in Optimality theory: constraints and representations (pp. 159-182). Cambridge University Press.

Syed Jaafar, S. R. (2010). Malay prefixation. Newcastle Working Papers in Linguistics (Vol. 16). Newcastle University, United Kingdom.

Urbanczyk, S. (1996). Pattern of reduplication in Lushootsheed. Ph.D dissertation, University of Massachusetts, Amherst.

\section{Notes}

Note 1. The data of SMD in this study are based on the data from Kuching only. The phonological analysis discuses in this study might not be right to represent other dialects spoken in Sarawak.

Note 2. The 'elements' used here refers to segments, i.e. higher-order units of prosodic structure such as moras, syllables, feet, heads of feet, tones and distinctive features or feature nodes (McCarthy and Prince, 1995). 